\title{
Variability and trends in indices of quality-controlled daily temperature extremes in Uruguay
}

\author{
Matilde Rusticucci ${ }^{\mathrm{a} *}$ and Madeleine Renom ${ }^{\mathrm{b} *}$ \\ a Departamento de Ciencias de la Atmósfera y los Océanos, FCEN, Universidad de Buenos Aires, Buenos Aires, Argentina

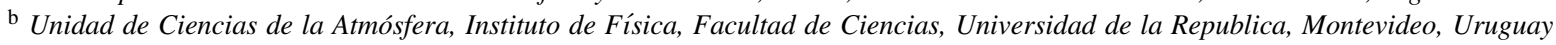

\begin{abstract}
A database of daily extreme temperature was created for as many stations as possible for Uruguay, as far back as possible. This is the first attempt to gather all the different data sources together, perform a quality control and homogeneity assessment. We work with seven stations; it should be taken into account that Uruguay is a small country (around $177000 \mathrm{~km}^{2}$ ) and this represents most of the available data. There are three old series with starting dates in 1930, and four that start around 1950. From this database, a set of four extreme temperature indices was constructed for the oldest five stations, warm days (TX90), cold days (TX10), warm nights (TN90) and cold nights (TN10).

The index TN10 shows the largest significant negative trend for the period 1960-2002, while TN90 shows a positive but not significant trend for this period indicating a strong warming of nighttime temperature. A spectral analysis was performed using the multi taper methods (MTM) to the de-trended annual, summer Dec-Feb (DJF) and winter Jun-Aug (JJA) indices time-series. This analysis shows that on inter-annual timescales, the most significant range of frequencies is from 2 to 2.5 years and from 3 to 6 years. Low frequencies of variability were detected when the MTM was applied to de-trended smoothed annual time-series, around the range of frequencies of 15-25 years for almost all the indices analysed. Links with global sea surface temperature (SST) were studied for two stations (Paysandu and Rocha), and it was found that the indices showed largest correlations with SST anomalies in the Pacific Ocean. We detected changes in the response of the TN10 index for Rocha station when the series was split up into two different periods (1942-1976 and 1977-2005). Copyright (C 2007 Royal Meteorological Society
\end{abstract}

KEY WORDS extreme temperature indices; trends; temporal variability; Uruguay

Received 8 February 2007; Revised 25 June 2007; Accepted 30 June 2007

\section{Introduction}

Climate extreme events have a strong impact on human activities. Identifying natural climate extreme variability is very important to understand the interaction between this kind of variability and that which is anthropogenically forced. Increasingly, climate change studies have focused on changes in extreme events, which require daily observations. The analysis of extremes in the present climate, and the detection of changes in their frequency and intensity require high quality and highfrequency datasets, which represents a major obstacle for this kind of study.

Earlier global analysis of extreme indices showed that South America is one of the regions of the world having poor data or no data at all, (Frich et al., 2002). In a recent global analysis of climatic extremes, based on the study of changes in extremes, South America was represented with really scarce station data obtained in regional workshops (Vincent et al., 2005; Alexander et al., 2006).

* Correspondence to: Matilde Rusticucci, Departamento de Ciencias de la Atmósfera y los Océanos, FCEN, Universidad de Buenos Aires, Buenos Aires, Argentina. E-mail: mati@at.fcen.uba.ar

Madeleine Renom, Instituto de Fisica, Facultad de Ciencias, Igua 4225, C.P. 11400, Montevideo, Uruguay. E-mail: renom@ fisica.edu.uy
The data span the relatively short period 1951-2003, and the quality is still poor. Moreover, most studies are based on the analysis of trends in climatic extremes.

Studies based on daily maximum and minimum temperatures in Argentina conclude that minimum temperature shows a significant positive trend in a large number of stations (Rusticucci and Barrucand, 2004). The trend analysis based on indices of daily temperature extremes confirmed and extended this result to all of South America (Vincent et al., 2005). No consistent changes were found in indices based on daily maximum temperature, but significant trends were found in indices based on daily minimum temperature. The relationship between extreme temperature events and sea surface temperature has been studied for Argentina, where extreme temperature events show high correlation with the sea surface temperature anomalies of the coastal waters in the South Atlantic and South Pacific (Rusticucci et al., 2003), which is even stronger than the influence of El Niño Southern Oscillation (ENSO) variability (Rusticucci and Vargas, 2002). There are no studies exploring the temporal variability of extreme temperature events in Uruguay.

Although Uruguay is a small country, it has old, daily time-series with starting dates around 1930. The data used 
in this study were recently digitized, and further work is in progress to continue the digitization of the other available stations in Uruguay. The main objective of this work is to analyse the trends and variability on interannual and inter-decadal timescales of four indices of extreme temperature. To do so, we first generate a daily database that takes into account all available station data in Uruguay. We also explore links between global SST and these temperature indices by means of a correlation analysis.

The paper is organized as follows: data are described in Section 2, which includes detailed descriptions of daily data and data quality control. In Section 3 we provide a detailed account of the different methodologies used. Sections 4,5 and 6 present the results of the homogeneity assessment, trend computation and temporal variability of the de-trended time-series of indices, respectively. Statistical correlations between the extreme temperature indices and sea surface temperature anomalies are explored in Section 7. Finally, Section 8 summarizes the results.

\section{Data}

\subsection{Description}

In Uruguay, there are currently 17 meteorological stations administered by the Uruguayan National Meteorological Service (Dirección Nacional de Meteorología, DNM), and five stations more operated by the National Agricultural Research Institute (Instituto Nacional de Investigaciones Agropecuarias, INIA). Until a few years ago, all the data from the DNM were in paper format; this, however, changed 3 years ago when data started to be digitized under the project IAI-CRN-055 PROSUR (Development of a Collaborative Research Network for the Study of Regional Climate Variability and Changes, their Prediction and Impact in the MERCOSUR Area), financially supported by the Interamerican Institute for Global Change (IAI) and CLARIS (A Europe-South America Network for Climate Change Assessment and Impact Studies), a project within the European Community 6th Framework Programme.

Of the 17 stations belonging to the DNM, five started in the 80s and were not considered in this study because they were too short. Another two stations were interrupted during four or more years and are not considered either. Of the remaining ten, we consider only the 6 stations that were in digital format at the time of this study. With respect to the stations operated by INIA, we only consider that of the La Estanzuela, because the rest of the stations were started in the $80 \mathrm{~s}$.

The data represent observations of daily maximum surface air temperature, $T x$, and daily minimum surface air temperature, $T n$, from seven meteorological stations. It should be noted that Uruguay is a small country (around $177000 \mathrm{~km}^{2}$ ) so, almost all the available data was used. As far as we know, this is the first attempt to gather all the different temperature data sources together over Uruguay. The stations used in this study are Salto, Paysandu, Mercedes, La Estanzuela, Carrasco, Rocha and Paso de los Toros. The geographical distribution of the stations is shown in Figure 1. Paysandu, Mercedes and La Estanzuela are the three oldest time-series with starting dates in 1930, located near the Uruguay River; Rocha

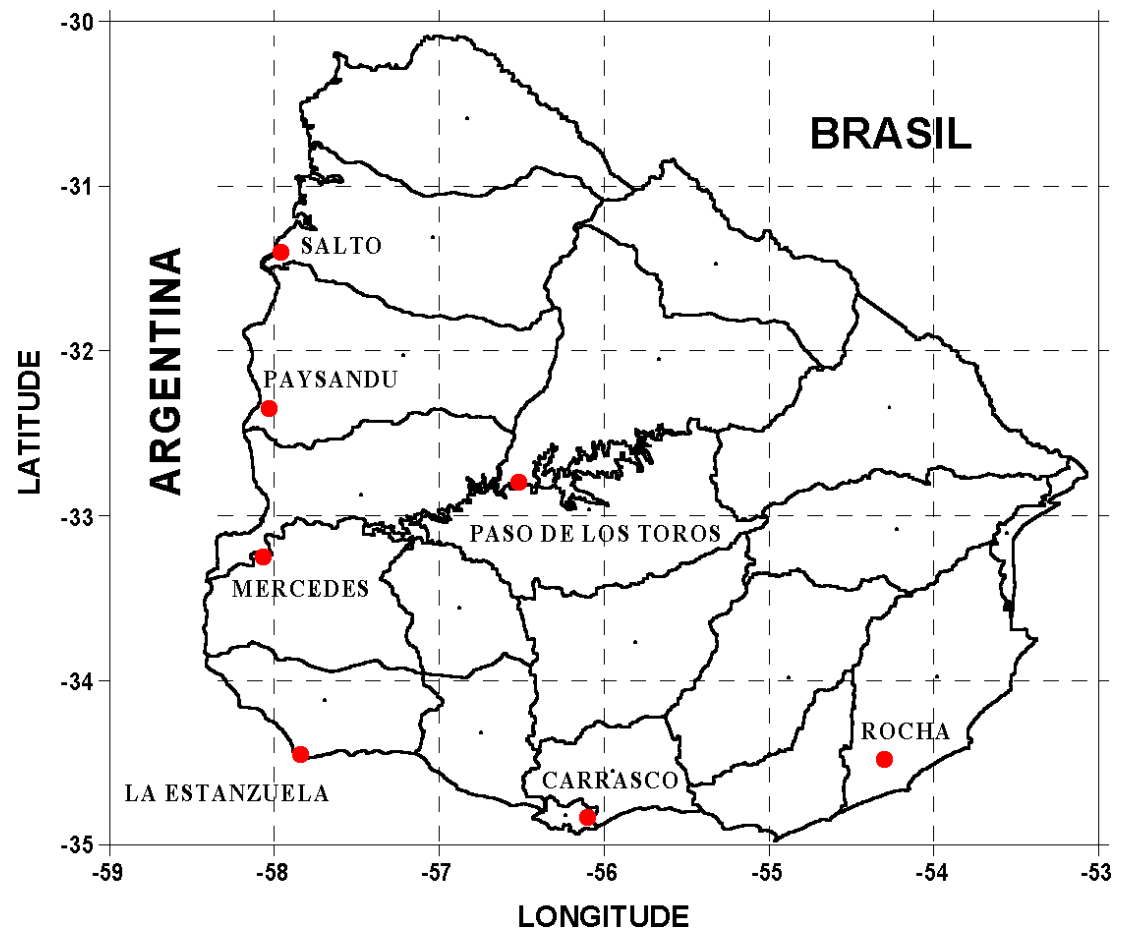

Figure 1. Location of the seven temperature stations analysed. This figure is available in colour online at www.interscience.wiley.com/ijoc 
station started in 1950, and Paso de los Toros in 1960, all of them finished in 2002-2005. Carrasco and Salto are the shortest, starting in 1970 and finishing in 2002.

When reading the data for the first time, we detected a high percentage of missing data. We tried to recover the data by reading the thermograph bands when they were available. The final rate of missing values is $4 \%$ over the total of daily data (maximum and minimum temperature). Although this percentage is low, the major problem is that the missing data are grouped in continuous days or months, which affects some homogeneity tests. In many stations there are periods of lost data that can span upto several months. Mercedes station has the maximum total percentage of missing data $(2.5 \%)$ while the other stations fluctuate between 0.1 and $1.5 \%$. Station La Estanzuela is complete.

In order to compare the homogeneity results obtained for the Uruguayan station, we have introduced the Argentinean meteorological station of Observatorio Central Buenos Aires (OCBA, $34^{\circ} 35^{\prime} \mathrm{S}, 58^{\circ} 29^{\prime} \mathrm{W}$ ), which is located in the city of Buenos Aires, Argentina. This station has an older time-series of maximum and minimum daily temperatures than the oldest station in Uruguay.

The monthly global-gridded SSTs used in this paper is the improved extended reconstructed SST (ERSST v.2) at $2^{\circ} \times 2^{\circ}$ latitude-longitude resolution for 1854-2005 (Smith and Reynolds, 2004). The annual anomaly of global SST is used to correlate with the different annual temperature indices.

\subsection{Quality control}

Data quality assessment is an important requirement before any calculation or analysis. For the quality control we first used the RClimDex 1.0 (freely available at http://cccma.seos.uvic.ca/ETCCDMI), a user-friendly software package (see Haylock et al., 2006; Alexander et al., 2006), which detects some common errors, such as maximum temperature cooler than minimum temperature and outliers. Because we found some errors that are not detected by this software, we also applied an additional test.

All suspicious daily temperatures were identified: maximum temperature cooler than minimum temperature, and outliers in daily maximum and minimum temperature. Outliers were considered when the values were outside a defined range. In this study, the range is defined as lying within four standard deviations of the climatological (1961-1990) mean of the value for the day. Daily temperature values outside this range were manually checked, case by case. Since we found that this last check did not detect some errors, we also controlled differences in temperature between two consecutive days in each station for maximum and minimum temperature. This last analysis is based on the persistence of the atmospheric data in order to detect other errors, such as typing errors. We established a threshold of acceptance for the variable tested, following the criteria applied for the Argentinean daily database (Rusticucci and Barrucand,
2001). We decided to control the cases when the interdiurnal difference on two consecutive days was higher than four times the standard deviation for each month. This procedure found more erroneous data, particularly in maximum temperature $(79 \%)$. The most common errors were typing errors and confusion between maximum and minimum temperature. In one station we found a complete month with erroneous data in both variables, which could be due to confusion when entering the data. This error was not detected by the RClimDex software.

The cases detected with this methodology, which statistically had a very low probability of occurrence, were not always erroneous data. Some large inter-diurnal differences could be associated with synoptic phenomena. An example of a large inter-diurnal difference due to a synoptic phenomenon is the case of 25 August 1996. On that day, three stations had a difference of upto $20^{\circ} \mathrm{C}$ in maximum temperature when compared to the previous day's maximum temperature. This case was also detected in Argentina (Rusticucci and Barrucand, 2001), suggesting that these data are not erroneous.

\section{Methodologies}

\subsection{Statistical homogeneity}

Different homogenization procedures were used for intercomparison purposes. They are based on different theories and different sensitivities in the detections of steps inside the time-series. The selected test methods are: the standard normal homogeneity test (SNHT) (Alexandersson, 1986); Buishand range test (Buishand, 1982) and the homogeneity test proposed by Vincent (1998) using regression models. The null hypothesis in the first two tests is that the testing variables are i.i.d., whereas, the alternative hypothesis assumes the existence of a stepwise shift in the mean. The test proposed by Vincent fits a linear regression to the data. If the autocorrelation of the residuals is significantly different from zero, this model is rejected, and a second model is used to identify the inhomogeneities.

The three selected tests can successfully locate the year where a break is likely to exist. The first two tests can detect a single step. The SNHT is good particularly at detecting breaks near the beginning and end of a series, whereas the Buishand range test is more sensitive to breaks in the middle (Hawkins, 1977). The Vincent test is capable of detecting multiple steps and is sensitive to identifying undocumented change points. This is a very useful property of the test, because there is a poor history of station reports in Uruguay. On the other hand, our database shows a weakness related to the requirement of a complete dataset. The method does not calculate monthly means if the time-series have more than three consecutive days of missing data or more than 5 days of missing data during the month; at the same time, if a monthly mean is missing, it does not calculate the annual mean. 
In the case of the SNHT and Buishand tests, we initially selected the annual mean of the diurnal temperature range (mDTR) as the tested variable, (Wijngaard et al., 2003). In some cases, we applied these tests to the annual mean maximum and minimum temperature time-series. The other test uses the annual mean of maximum and minimum temperature as the tested variable separately.

To better inter-compare the inhomogeneities in the time-series, we broke up the total period into two parts. Sub-periods are of no less than 30 years in order to maintain the statistical stability of the test. The periods are considered from the beginning of the oldest timeseries (Paysandú, Mercedes and La Estanzuela) until 1970, and from 1971 to 2002 . The rest of the stations are considered over their whole record, except for Salto station, which is analysed from 1977-2002 to avoid a documented change of location in 1976.

\subsection{Trends of temperature indices}

A set of 4 temperature indices related to the frequency of warm days (TX90), cold days (TX10), warm nights (TN90) and cold nights (TN10) was constructed, using the RClimDex software, for each station and calculated on a monthly and/or annual basis. These warm (cold) temperature indices based on percentiles are calculated as percentage of days (in a month or year) above (below) the 90th (10th) percentile. The percentiles are calculated from a 5-day window centered on each calendar day from the reference period 1961-1990.

Salto and Carrasco stations have the shortest series, and the base period considered (1961-1990) is not included in the time-series of these stations. Because of this, their temperature indices could not be constructed and will not be considered in this study.

The best-fit linear trend is often used to describe changes in a climatological series. For this purpose, we use a non-parametric method in determining the presence of slope. The estimator is the median of the slopes obtained from all joining pairs of the point series (Sen, 1968). The statistical significance of the trends was assessed at the 5\% level. To look at the inter-decadal changes in trends, calculations were performed for three periods: 1935-2002 (three stations), 1950-2002 (four stations) and 1961-2002 (all five stations). These periods were chosen to account for the different starting dates of the available time-series.

\subsection{Temporal variability}

The spectral analysis of the temporal time-series of temperature indices was performed using the multitaper method MTM (Percival and Walden, 1993). The statistical significance of the spectral peaks is determined using the chi-square test under the null hypothesis of red noise.

The MTM was applied to the temperature indices and to 10 -year smoothed indices.

\section{Homogeneity Assessment}

Homogeneity assessment and adjustment can be quite complex for a daily data-base (Vincent et al., 2002) and it often requires close neighbour stations, detailed station metadata and a great amount of time. Therefore, the objective was to identify only the potential major problems. Selecting the correct testing variable is very important to study inhomogeneities. The Salto station has a documented relocation in 1976, which was not detected when the annual mDTR is used as a testing variable. On the other hand, a significant step at the $1 \%$ level is detected in 1976 when $T x$ and $T n$ are analysed. This example suggests that using $\mathrm{mDTR}$ as a testing variable is not always sensitive to changes, especially when they have the same effect on the maximum and minimum temperatures (because of the construction of mDTR, the differences between daily maximum and minimum temperatures remain the same).

The most frequently encountered causes for the breaks detected in the temperatures series were station relocations or changes in observing practices. Historic metadata support is essential for evaluating the breaks detected as well as for future attempts to correct series from artificial steps. Unfortunately, these metadata are very poor in Uruguay because not all the relocations of stations are documented, and changes in instrumentation locations and measuring techniques are even more poorly so.

It is worth mentioning that we found significant shifts around the same years in more than one station. One of them is around 1938-1939, detected in the oldest time-series of Mercedes and La Estanzuela. To verify a possible climatic origin of this shift, we used the daily series of maximum and minimum temperatures from OCBA station, Buenos Aires, Argentina. The tests detected a shift at around 1939 in the OCBA series, as well as in a preliminary study of Prado station $\left(34^{\circ} 51^{\prime} \mathrm{S}\right.$, $56^{\circ} 12^{\prime} \mathrm{W}$, Uruguay) during the period 1921-1969. The shift seems to be significant for minimum temperature and was detected when the whole period is considered as well as when the series was split into sub-periods.

The other shift present in more than one station was detected by the SNHT test in 2001. This test applied to the annual mean minimum temperature during 1971-2002 detected a shift around 2001 in Paysandú, Mercedes, La Estanzuela, Carrasco and Rocha stations; this shift is significant at the $1 \%$ level. The annual mean of minimum temperature during 1971-2002 presents the highest minimum temperature of the period in 2001, with a maximum standard deviation of around $1.5^{\circ} \mathrm{C}$ for all the stations considered.

A summary of the tests applied to all stations is shown in Table I. The table describes the years when a significant change was detected by each of the tests, as well as the variable tested, and their significance levels. In the case of Mercedes and Paysandu, it is important to mention that the documented change of location in 1977 for the first one, and in 1967 for the second, is not detected by any of the applied tests. 
Table I. Results of Homogeneity Test applied. SNHT: bold, Buishand: italic, Vincent et al.: Underlined. Significance: ${ }^{* *}: 1 \%,{ }^{*}: 5 \%,{ }^{\wedge}: 10 \%$. The steps in years $1938-1939$ and 2001 were detected in more than two stations.

\begin{tabular}{|c|c|c|c|}
\hline Station & Period & Vble & Change points \\
\hline \multirow{4}{*}{ Salto } & \multirow[b]{2}{*}{ 1970-2002 } & $\mathrm{Tx}$ & $1_{1976}^{* *} 1997^{* *}$ \\
\hline & & $\mathrm{Tn}$ & $\overline{1976^{* *}}$ \\
\hline & \multirow{2}{*}{$1977-2002$} & mDTR & $\overline{1998}$ \\
\hline & & $\mathrm{Tx}$ & $\underline{1998^{*}} 1997^{* *}$ \\
\hline \multirow{7}{*}{ Paysandu } & \multirow{3}{*}{$1935-2002$} & mDTR & $1946^{* *} 1957^{* *} 1989^{*}$ \\
\hline & & $\mathrm{Tn}$ & $1957^{* *} 1969^{* *}$ \\
\hline & & $\mathrm{Tx}$ & $1946^{* *} 1977^{* *} \mathbf{1 9 4 5}^{*}$ \\
\hline & \multirow{3}{*}{$1935-1970$} & mDTR & $\overline{1945^{* *} 1957^{* *}}$ \\
\hline & & $\mathrm{Tx}$ & $1945^{* *} 1954^{* *}$ \\
\hline & & $\mathrm{Tn}$ & $1957^{* *}$ \\
\hline & $1971-2002$ & $\operatorname{Tn}$ & $1996^{*} 2001^{* *}$ \\
\hline \multirow{6}{*}{ Mercedes } & \multirow{3}{*}{$1931-2002$} & mDTR & $1997^{*}$ \\
\hline & & $\mathrm{Tn}$ & $\underline{1940^{* *}} 1997^{*}$ \\
\hline & & $\mathrm{Tx}$ & $\underline{1942^{*}}$ \\
\hline & $1931-1970$ & $\mathrm{Tn}$ & $1939^{* *}$ \\
\hline & & mDTR & $1996^{*} 2001^{*}$ \\
\hline & $1971-2002$ & $\mathrm{Tn}$ & $\underline{1983^{\wedge}} 1997^{* *} 1985^{*}$ \\
\hline \multirow{7}{*}{ La Estanzuela } & \multirow{3}{*}{$1931-2002$} & mDTR & 1935** $^{* * 1982}{ }^{*} 1945^{*}$ \\
\hline & & $\mathrm{Tn}$ & 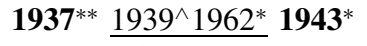 \\
\hline & & $\mathrm{Tx}$ & $1935^{*} 1945^{*}$ \\
\hline & \multirow[b]{2}{*}{$1931-1970$} & mDTR & $1935^{* *} 1945^{*}$ \\
\hline & & $\mathrm{Tn}$ & 1938** $^{\text {** }}$ 1935* $^{*} \underline{1939^{*} 1962^{\wedge}}$ \\
\hline & & mDTR & $1982^{*}$ \\
\hline & $1971-2002$ & $\mathrm{Tn}$ & $2001^{*}$ \\
\hline \multirow{3}{*}{ Carrasco } & \multirow{3}{*}{$1970-2002$} & mDTR & $1976^{* *}$ \\
\hline & & $\mathrm{Tx}$ & $\underline{1976^{* *}}$ \\
\hline & & $\mathrm{Tn}$ & $2001^{*}$ \\
\hline Paso de los Toros & $1960-2002$ & $\mathrm{Tn}$ & $1967^{* *}$ \\
\hline \multirow{2}{*}{ Rocha } & \multirow{2}{*}{$1950-2002$} & mDTR & $1978^{*} 1990^{*}$ \\
\hline & & $\mathrm{Tn}$ & $1979 * 1990^{*} 2001^{*}$ \\
\hline
\end{tabular}

The identified inhomogeneities can affect the trends calculated in some temperature indices. However, removing all suspicious sites could have resulted in almost no stations for the trend and variability analyses in Uruguay. Therefore, the homogeneity results were used in this study for explaining the trends that were not in line with those resulting from the surrounding stations.

\section{Trends}

The analysis is based on four extreme temperature indices for five stations (see Section 3.2).

Figure 2 presents a map with the slopes of the trends for the indices based on daily maximum temperature. In La Estanzuela station, the trend of TX90 is negative in all the periods considered although it loses its statistical significance in the last period. A change in sign occurs at the Paysandu station: while the trend in the whole period (1935-2002) is negative, it changes to positive during 1950-2002 and 1961-2002, although neither positive nor negative trends are significant. This could be due to the steps detected in the homogeneity test around 1945 in the maximum temperature. TX10 show a negative trend in all periods considered, except in the Paso de los Toros station. When studying the trends in the indices based on minimum temperature, we found that TN90 show positive trends in all the periods and for all the stations. However, the trends are significant for only one station in each period (Figure 3). The most profound changes are observed in the percentage of TN10. Almost all the stations show significant decreasing trends in the percentage of cold nights, while the last period analysed, 1961-2002, shows the most decreasing trend, around $-1.2 \% /$ decade compared to the other periods studied, with trends around $-0.7 \% /$ decade. This indicates a strong warming of nighttime temperature with fewer TN10 and more TN90, in accordance with other regional results (Rusticucci and Barrucand, 2004; Vincent et al., 2005).

Another test for the existence of linear trends was applied where the significance of the linear slope was considered at the 5\% level (Hoel, 1971). Overall, this test shows higher significance than the Sen estimator for all the indices. 
Trends Warm Days

1935-2002

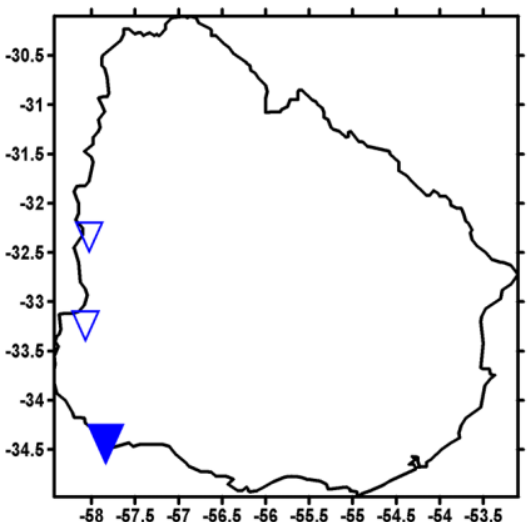

1950-2002

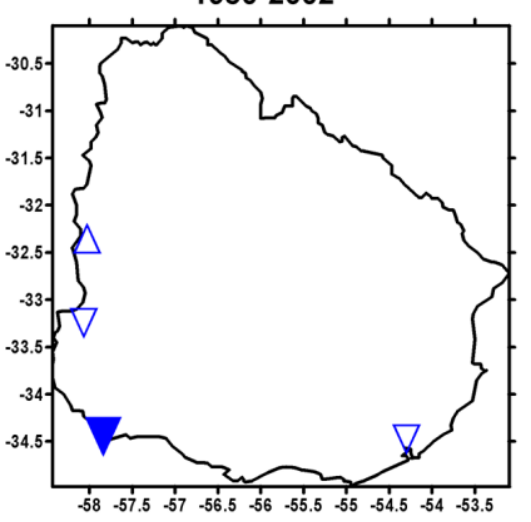

1961-2002

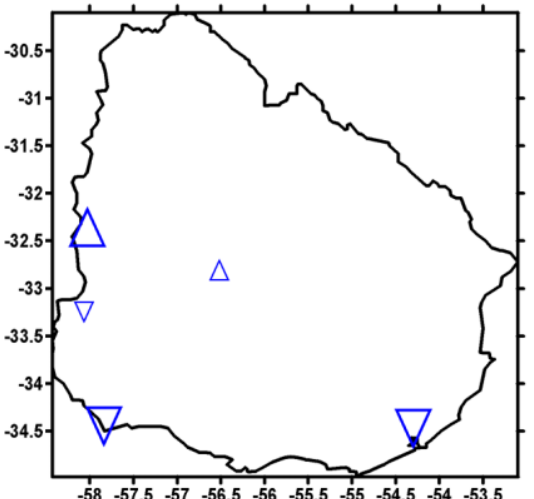

Trends Cold Days

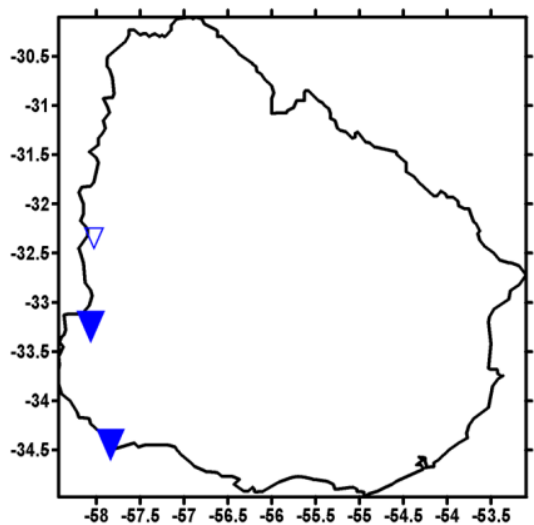

$\bigvee^{-1}$ to -0.6

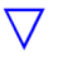

$\nabla$

-0.6 to -0.2

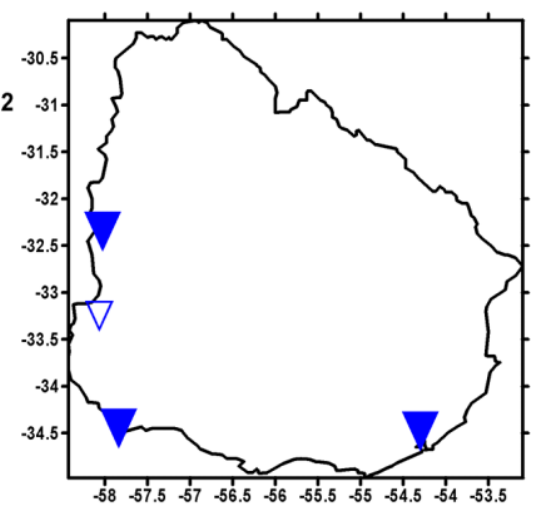

1 to 2

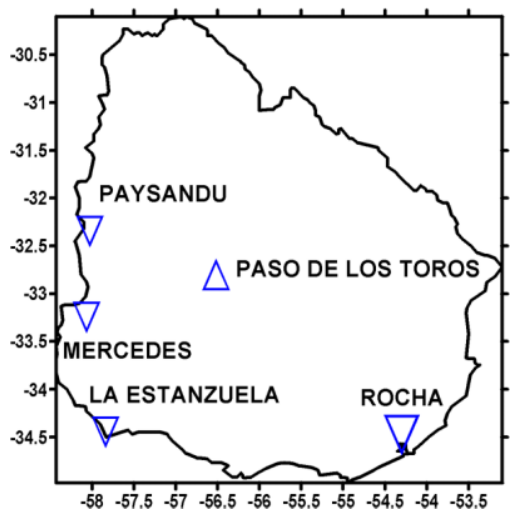

Figure 2. Slope of the trends (in percentage/decade) for two indices based on daily maximum temperature over three periods: 1935-2002, 1950-2002, and 1961-2002. Upward and downward pointing triangles indicate positive and negative trends, respectively. Filled triangles correspond to trends significant at the 5\% level. Size of triangle is proportional to the magnitude of the trend in $\%$ per decade. This figure is available in colour online at www.interscience.wiley.com/ijoc

\section{Temporal Variability}

Because the trend analysis shows significant trends in almost all the indices studied, the MTM methods were applied to de-trended annual time-series of TN10, TN90, TX10 and TX90. These time-series are shown in Figures 4 and 5 . All of them were smoothed in time by a 10 -year running mean. The smoothed time-series are also presented. Note that for TN90 the absolute maximum in all the stations analysed occurs in 2001, which implies that this year showed the highest percentage of days with
TN90, in accordance with the inhomogeneity previously detected in the homogeneity analysis (see Section 4).

\subsection{Interannual variability}

The multi-taper spectrum for a 70-point time-series, using a $p=2$ tapers, allows a half-bandwidth spectral resolution of $p \mathrm{fR}=0.028 \mathrm{cy} / \mathrm{yr}$ (where $\mathrm{fR}$ is the Rayleight frequency). In this case, for the TN90 index from Mercedes station, we found spectral peaks, significant at the $5 \%$ level at periods of 3.4 and 2.4 years; another peak significant at the $10 \%$ level occurs at 4.7 years. The spectra 
Trends Warm Nights
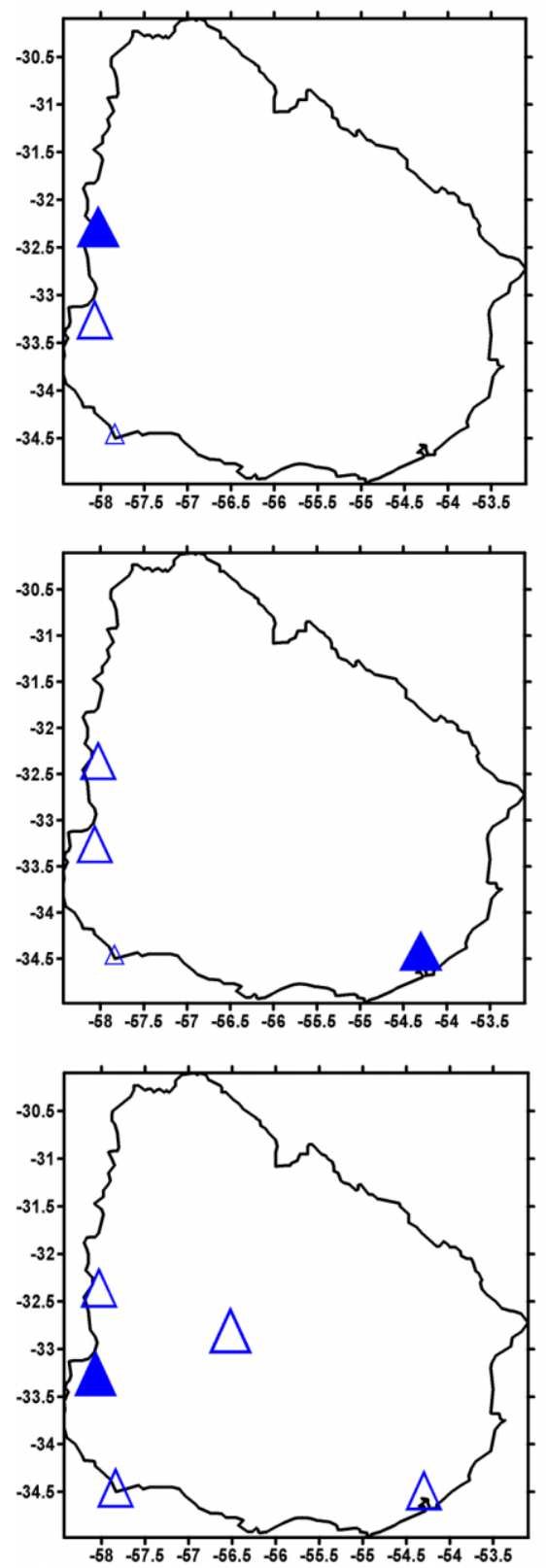

Trends Cold Nights

1935-2002

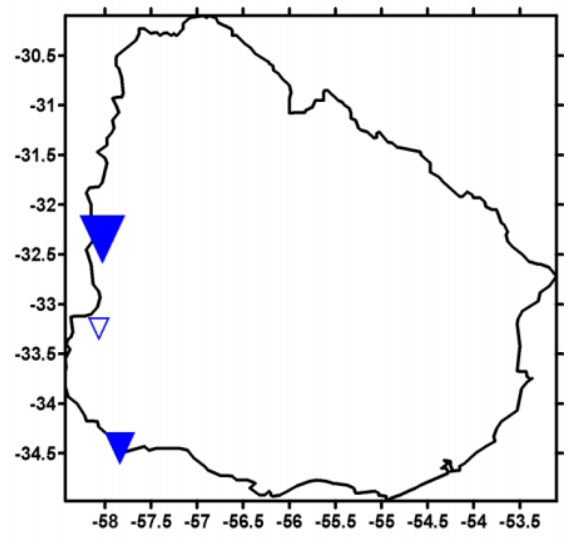

1950-2002
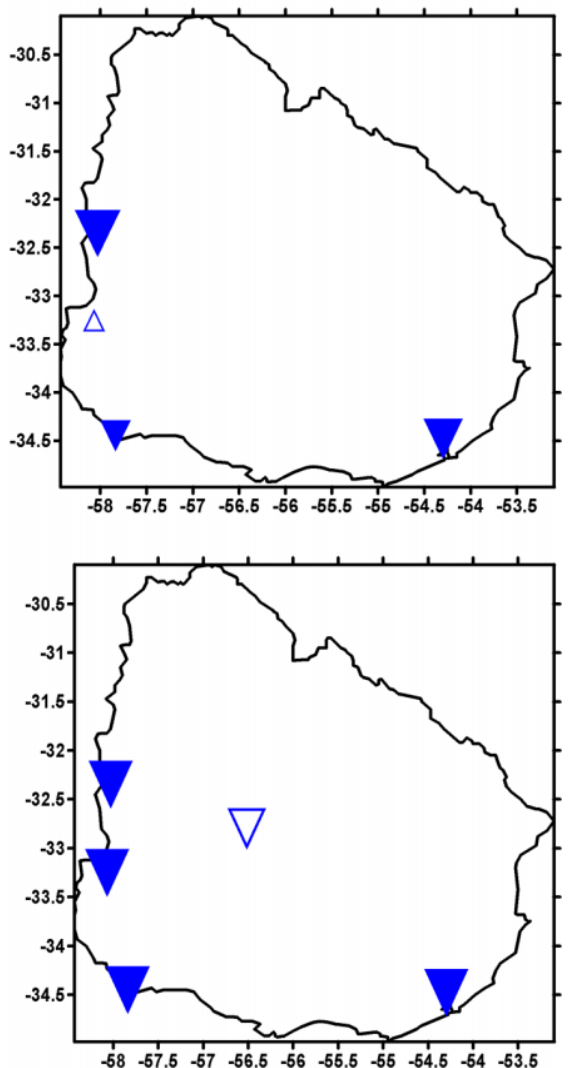

Figure 3. Same as Figure 2 but for indices based on daily minimum temperature. This figure is available in colour online at www.interscience.wiley.com/ijoc

of all indices exhibit peaks (significant at the $5 \%$ level) at periods between 3 and 5 years, which may be associated with the ENSO phenomenon. A quasi-biennial oscillation is found at periods of $2-2.5$ years significant at the $1 \%$ level. For TN90, peaks between 8 and 10 years appear to be significant at the $10 \%$ level for all the stations studied. A similar result was found for TX90, but the peaks are not as significant for Mercedes and Paso de los Toros stations. These different periods of variability detected in the indices of extreme temperature were also detected in the annual runoff in eastern South America of the Negro, Paraguay, Paraná and Uruguay Rivers (Robertson and Mechoso, 1998). The analysis identified a low-frequency peak (33-year period) in the TX10 of La
Estanzuela, significant at the $10 \%$ level; a similar result was found in Mercedes, but for TN10. We also studied the variability of summer (DJF) and winter (JJA) timeseries. The biennial variability detected is more important in summer (significant at the $1 \%$ level) than in winter. The same result was found for the Argentina stations (Rusticucci and Vargas, 2001). A peak between 3 and 6 years appears in summer as well as in winter, but it is more significant in winter. Low-frequency variability (22-30-year periods) is apparent in summer for TN10 in Mercedes and La Estanzuela.

6.2. Decadal to multi-decadal variability

In the MTM spectra, using the de-trended and smoothed time-series of all the indices, we found a significant peak 
TX90
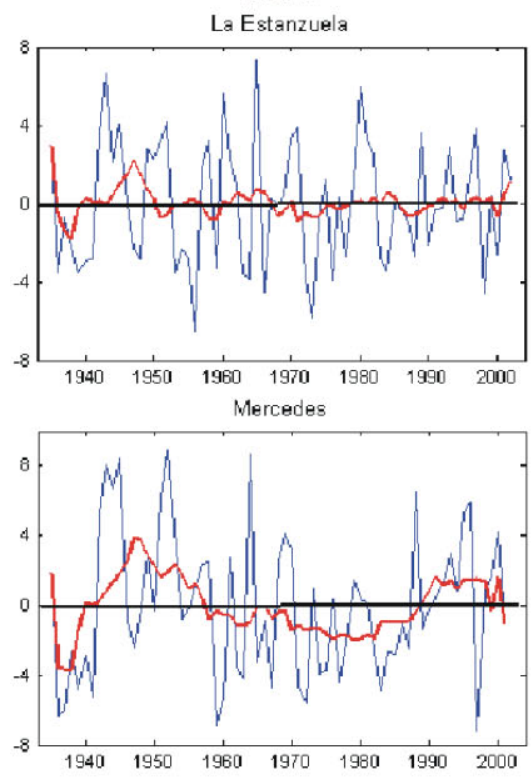

Paysandu
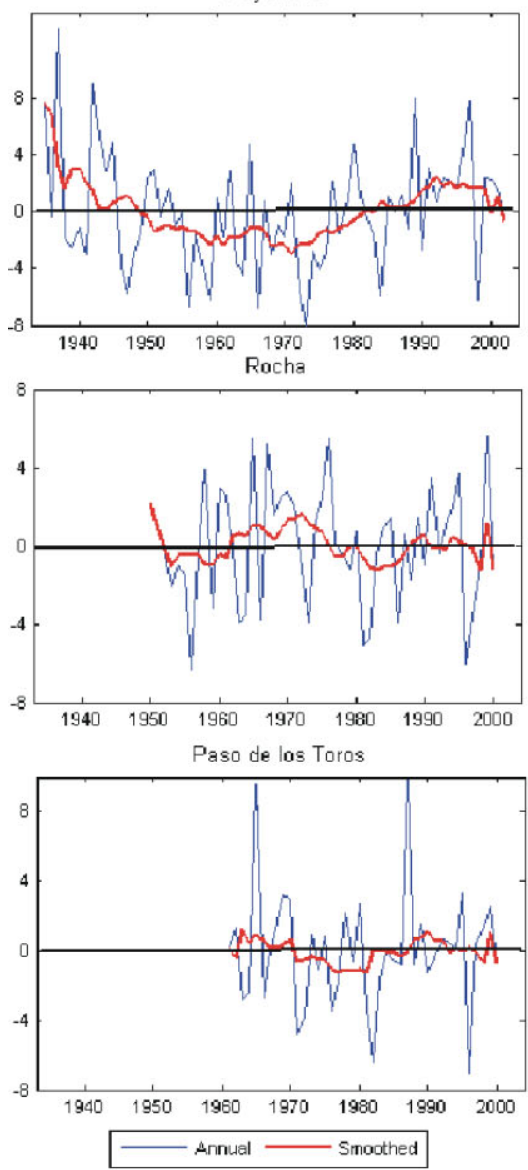

TX10
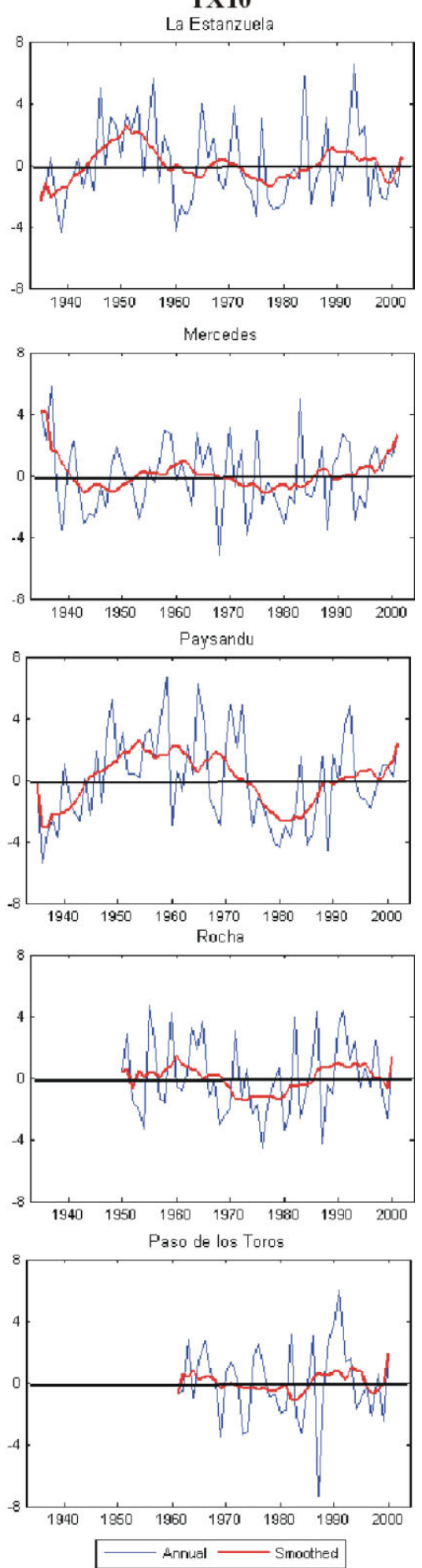

Figure 4. De-trended annual time-series (blue) and smoothed with a 10-year running mean (red) of indices based on maximum temperature (TX90, TX10). This figure is available in colour online at www.interscience.wiley.com/ijoc

(at the 1\% level) at 15-25 years in four of the stations analysed in all indices. Paso de los Toros presents a statistically significant peak at 12.5 years, which could be due to the shortness of the time-series for this station (40 years). The summer spectra of TX90, TX10 and TN10 indices exhibit a significant peak (at the 5\% level) at the same period (15-25 years), while for TN90, this peak is significant for La Estanzuela, Mercedes and Paysandú. Rocha and Paso de los Toros do not have significant peaks in the MTM spectra for TN90. The winter spectrum of TN90, TN10, TX90 and TX10 show a significant peak (at the 1\% level) in the inter-decadal 

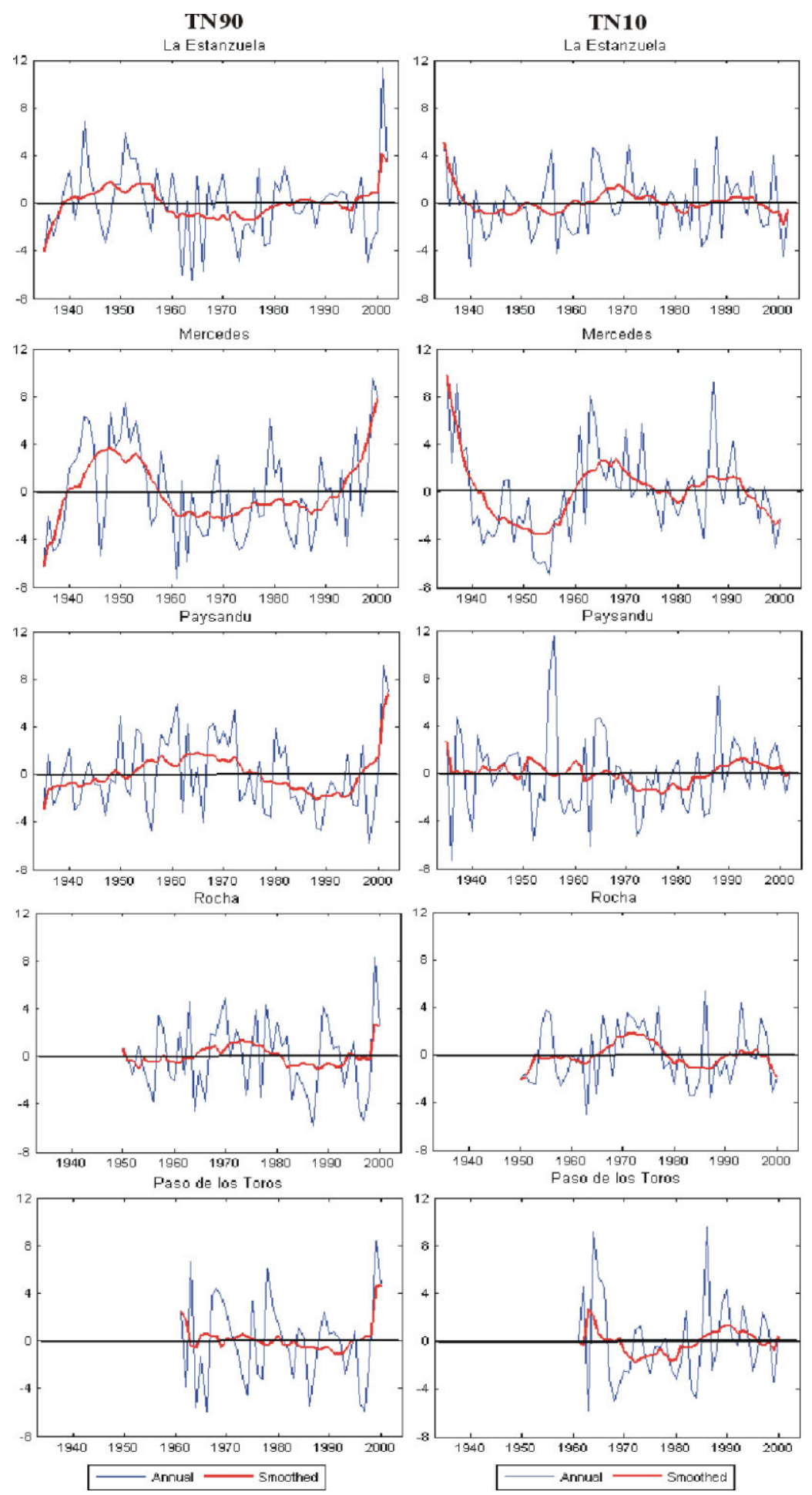

Figure 5. Same as Figure 4, but for indices based on minimum temperature (TN90, TN10). This figure is available in colour online at www.interscience.wiley.com/ijoc

timescale, with periods around 20 years in all stations except Paso de los Toros.

\section{Links Between SST and Extreme Temperatures in Uruguay}

For this analysis, we selected the Paysandu and Rocha stations because they tend to show a significantly different behaviour regarding some of the temperature indices. We studied the relationship between the detrended annual series of temperature indices and the annual anomaly of SST within the 3-6-year range and the 10-20-year range, in the period 1942-2005.

\subsection{Low-frequency correlations}

The correlation map between the TN10 index and SST anomalies for the Pacific Ocean has the same spatial pattern for both stations (Paysandu and Rocha), 
(Figures 6 and 7). A negative correlation was found along the southeastern and northeastern Pacific, with largest values to be found in the tropics. Also present, is a weaker band of positive correlation from central North Pacific and along the South Pacific convergence zone (SPCZ) through the sub-tropical southcentral Pacific. This correlation pattern has a spatial structure similar to the SST anomalies that characterize the Pacific decadal oscillation (PDO). Both station present statistically significant correlation at the 5\% level with PDO index, freely available at http://jisao.washington.edu/pdo/PDO.latest (Mantua et al., 1997). To quantify this relationship, we compare the number of days per year of TN10 for Rocha during the negative phase of PDO (1950-1976) with the number of days per year in positive phase of PDO (1977-2002). We found that during the negative PDO, the mean of days per year with extreme cold nights totaled 41, while for positive PDO it was 31 days.

Positive correlations between the TN10 index from Paysandu station were found for the tropical South Atlantic Ocean (approx. $15^{\circ} \mathrm{S}$ ) and towards the northern Atlantic. For Rocha, this index presents a positive correlation from $15^{\circ} \mathrm{N}$ towards the South Atlantic Ocean. A centre of negative correlation located in the South Atlantic Ocean along the eastern coast of South America is present in both correlation maps, but, surprisingly, it is only significant for Paysandu, but not for Rocha, which is located along the Atlantic coast.

***The correlations between the TN90 index and the Pacific Ocean for both stations have the same spatial structure as for the TN10, but they show a change

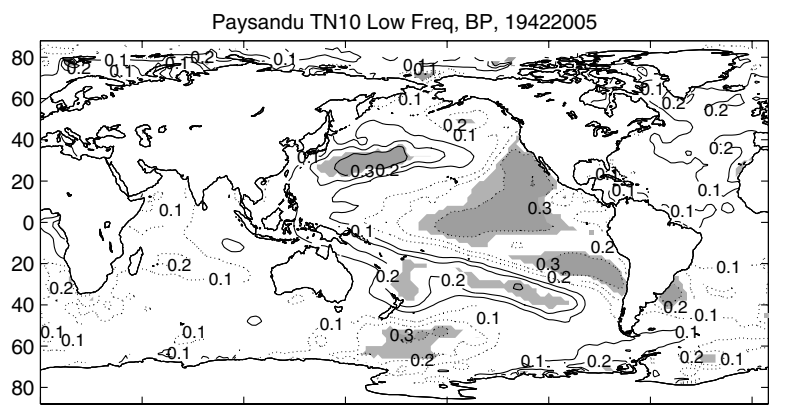

Figure 6. Correlations between TN10 index from Paysandu station and SSTs annual anomalies, with a band pass filter of $10-20$ years for the period 1942-2005. Significant correlations at the 5\% level are shaded.

Rocha TN10 Low Freq, BP, 19422005

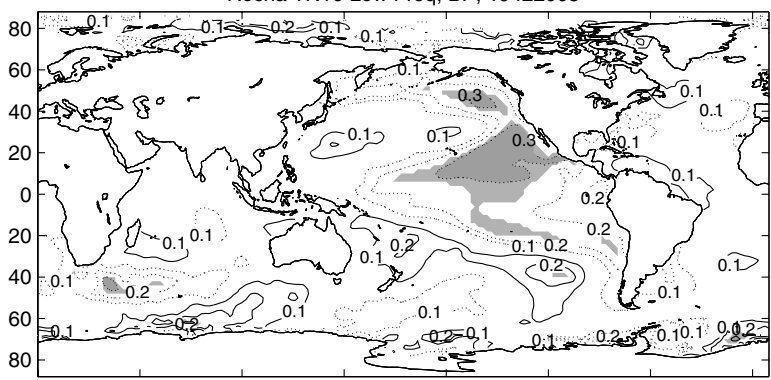

Figure 7. Same as Figure 6 but for Rocha station. in the sign of the correlation and a reduced statistical significance.

The TN90 index and the Atlantic Ocean present a negative correlation, except along the eastern coast of South America, which is significant for both stations, with higher correlations (around 0.5) for Paysandu station (not shown).

Paysandu presents two regions of significant correlation in the tropical to South Altantic Ocean; a positive (negative) one along the eastern coast of South America and a negative (positive) one along the western tropical coast of Africa, for TN90 (TN10).

The indices based on maximum temperature (TX10 and TX90) present, in general, lower correlations with global SSTs.

\subsection{High-frequency correlation}

This analysis was performed for both Rocha and Paysandú stations, but we are mainly presenting here the results for the former because they are the most interesting.

Overall, the correlation structures in this frequency band are the same as for the low-frequency variability for almost all the indices analysed, of both stations.

For the TN10 index from Rocha station, a large increase in the correlation with the central equatorial Pacific and the sub-tropical southcentral Pacific was detected for this range of frequencies (Figure 8) presenting a dipole in correlation between those Pacific zones.

The index based on minimum temperature for Rocha station presents a statistically significant correlation with the equatorial Pacific Ocean for this range of frequencies. In order to explore if the 1977 change in Pacific climate (Trenberth, 1990) affected these temperature indices, we analysed two periods: 1942-1976 and 1977-2005.

The TN10 index presents a change in the correlation structure between the different periods, (Figures 9 and 10). It is possible to clearly see a major weakening of correlation with the Pacific Ocean during the last period (1977-2005) with respect to the first one. There is also a weakening and an eastern displacement of correlations in the south Indian Ocean, as well a change of sign in this northern basin. On the other hand, an increase in positive correlation with the tropical

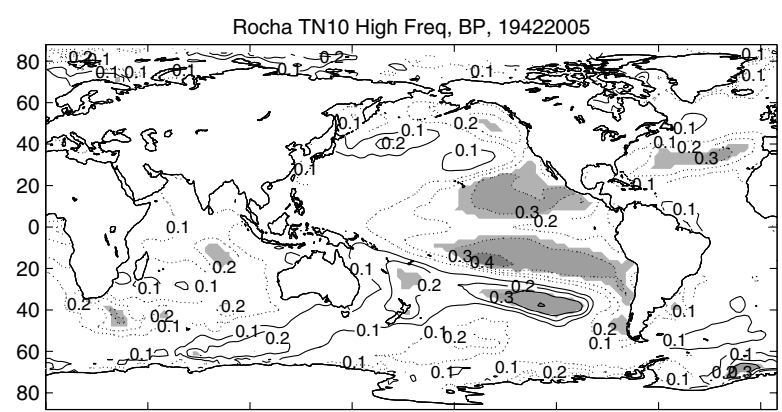

Figure 8. Correlations between TN10 index from Rocha station and SSTs annual anomalies, with a band pass filter of 3-6 years for the period 1942-2005. Significant correlations at the 5\% level are shaded. 


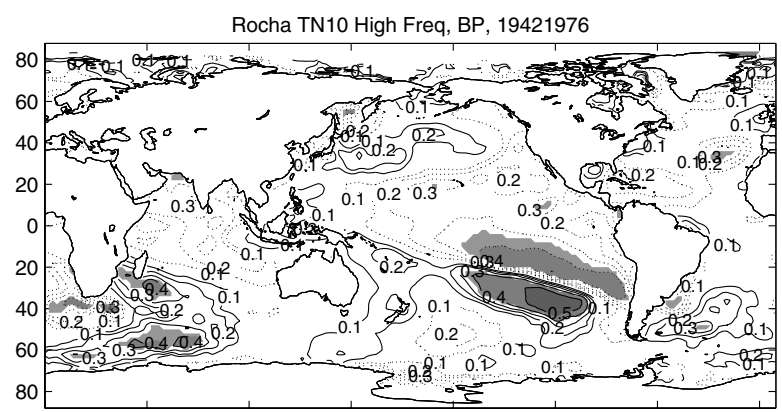

Figure 9. Correlations between TN10 index from Rocha station and SSTs annual anomalies, with a band pass filter of 3-6 years for the period 1942-1976. Significant correlations at the 5\% level are shaded.

Rocha TN10 High Freq, BP, 19772005

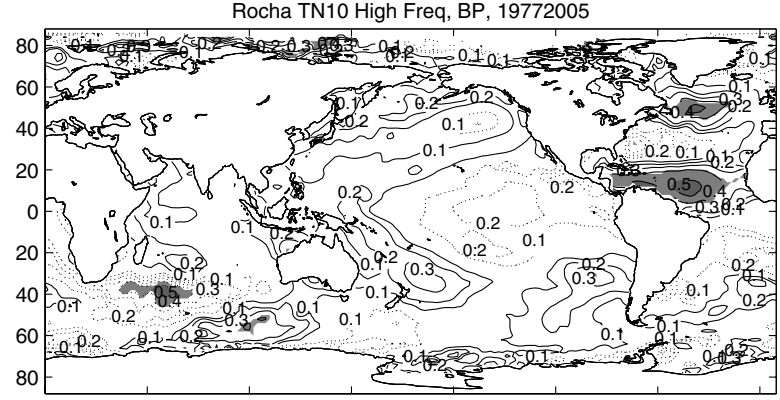

Figure 10. Same as Figure 9 but for the period 1977-2005.

and northern Atlantic is detected in this last period. For TN90 during the last period analysed, the western Pacific changes the correlation sign (positive to negative), with a strengthening of negative correlation along the SPCZ through the southern and eastern Pacific. The positive correlation, on the other hand, shows an eastern displacement through the equatorial Pacific. In the South Atlantic Ocean, there is an intensification of positive correlation along the eastern coast of southeastern South America, as well as a region with negative correlation in the tropical Atlantic (not shown). As to the Paysandu station, no changes in correlations with global SSTs were detected when we split up the series (not shown).

Recent studies about changes in observed precipitation in the Parana-Plata hydrological basin have shown a northward displacement of ENSO-induced precipitation during November in the last period analysed, when two different periods were compared (1950-1975 and 1976-2001) (Boulanger et al., 2005).

\section{Conclusions}

In this study, we generate a reliable daily database of maximum and minimum temperatures for seven Uruguayan stations.

Regarding the homogeneity tests applied, it is important to mention that the documented relocation of stations was not always detected; this implies that relocations do not induce a step in the series, in the cases of Mercedes, Paysandú and Paso de los Toros stations. On the contrary,
Salto and Carrasco stations show the artificial step generated in maximum and/or minimum temperature series because of the relocation.

Making adjustments to inhomogeneous series could be a method to improve the series in this dataset. Different homogeneity adjustment techniques were developed to eliminate artificial steps in the series (Peterson et al., 1998 present a review of them). However, adjusting on a daily basis is not so easy (Vincent et al., 2002). Here we do not try to adjust the series for the inhomogeneities detected; this is something to be addressed in future studies.

A change around 1939 was detected in minimum temperature time-series from the oldest stations in Uruguay, Mercedes and La Estanzuela. To eliminate possible breaks due to changes in instrumentations, observing practices and measurement techniques, we study the OCBA and Prado (during 1921-1969) temperature series. We obtained similar results, concluding that it was a real change.

The SNHT detected a step in 2001 annual mean minimum temperature series from five stations in the sub-period 1971-2002. Moreover, the analysis of annual 1971-2002 anomalies in all stations (except Salto) shows a strong warming in 2001. This year represents an interesting case study for future research.

A set of four temperature indices was constructed for the oldest stations. The indices are related to the frequency of TX90, TX10, TN90 and TN10, calculated on a monthly and/or annual basis. To better recognize different variability scales, we analyse trends in the time-series of extreme temperature indices. The most profound change was detected in the percentage of days with TN10, which shows the most decreasing trend in 1961-2002 with respect to the other periods considered. The only index showing a positive trend was TN90, but not significant. These results are indicative of a strong warming of nighttime temperature, with fewer TN10 and more TN90. This change is more significant in the last period (1961-2002) analysed than changes during other periods considered. For indices based on daily maximum temperature we found that TX10 present a negative trend in all periods considered, except for Paso de los Toros station. It is in the period 1950-2002 that this trend is significant at the $5 \%$ level. Because of the result obtained by the trends analysis, and in order to identify natural variability, the multi taper method was applied to the detrended annual, summer (DJF) and winter (JJA) seasonal series of the four indices. On inter-annual timescales, we found peaks between 3 and 5 years statistically significant at the 5\% level that may be associated with ENSO. A quasi-biennial oscillation at periods of 2-2.5 years was found to be even more significant (at the 1\% level) than the oscillation mentioned above. A peak near decadal scales was found for the warm tails of the indices studied (TX90 and TN90) in almost all the stations, significant at the $10 \%$ level. Low-frequency peaks were found in La Estanzuela and Mercedes for TX10 and TN10 respectively. Analysing seasonal time-series, we 
found that the biennial oscillation is more important for summer than for winter, while oscillations between 3 and 6 years are more significant for winter than for summer. For summer TX10, low-frequency variability was detected for two of the oldest series analysed. To identify the variability found on older timescales, the de-trended time-series were smoothed in time by a 10-year running mean. Significant peaks on interdecadal timescales (15-25 years) were found in all of the indices. Only Paso de los Toros stations do not present a significant peak on this scale that may be due to the shortness of the time-series (40 years). Analysing the links between temperature indices and global SSTs anomalies, we can conclude that the indices based on maximum temperature (TX90 and TX10) of the stations studied present, in general, a lower correlation with SSTs anomalies in both ranges of frequencies analysed. The indices based on minimum temperature, TN10 (TN90) have a significant negative (positive) correlation in the Pacific Ocean, with a PDO structure, in accordance with the significant peaks in the inter-decadal timescale found with the MTM. We compare the number of days per year of TN10 for Rocha during the different phases of PDO. We found a $25 \%$ decrease in the number of days per year with TN10 for positive PDO compared with negative phase.

Significant correlations in the South Atlantic Ocean were found for Paysandu, but not for Rocha, which is located over the Atlantic coast.

For the band of frequencies between 3 and 6 years, we found that both stations show similar correlations structures to the low-frequency variability, but slightly higher. In order to explore if the 1977 PDO phase change affects the correlation structure, two different periods were analysed: 1942-1976 and 1977-2005. A large weakening of correlation with the Pacific Ocean, losing its significance, as well as an increase in positive correlation with tropical and northern Atlantic, was detected during the last period compared with the first one for TN10 index in Rocha station. For TN90, we found for the last period a change in sign for correlation with the western Pacific, while there was, at the same time, a strengthening of negative correlation along the SPCZ through the southeastern Pacific. The differences in the correlations structure with TN10 and TN90 indices, during the two periods analysed, could be due to the change in phase of the PDO, which modulates the ENSO events. Many studies show differences in the circulation response over the Southern Hemisphere during ENSO, influenced by the inter-decadal variability (Zhang et al., 1997; Vera et al., 2004). Changes in precipitations anomalies in southeastern South America, related to a different response of ENSO and PDO, are also documented (Andreoli and Kayano, 2005; Boulanger et al., 2005; Kayano and Andreoli, 2007). Changes in the Pacific Ocean affect particularly minimum temperature, and this could account for the strong warming detected in the trend analysis during the last period. These results suggest the need for a better understanding of the variability of extreme events in Uruguay.

\section{Acknowledgements}

The authors would like to thank A. Carril and E. Scoccimarro for their help on some of the processing techniques (Scoccimarro E and Carril A, 2006: MATLAB and Practical Applications on Climate Variability Studies. Educational kit available online at 'Earth prints repository' http://hdl.handle.net/2122/1044). We would also like to thank M. Barreiro for his useful comments. This work was partially funded by Grants ANPCyT PICT05-38273, CLARIS-UE and IAI CRN055.

\section{References}

Alexander LV, Zhang X, Peterson TC, Caesar J, Gleason B, Klein Tank AMG, Haylock M, Collins D, Trewin B, Rahimzadeh F, Tagipour A, Rupa Kumar A, Revadekar J, Griffiths G, Vincent L, Stephenson DB, Burn J, Aguilar E, Brunet M, Taylor M, New M, Zhai P, Rusticucci M, Vazquez-Aguirre JL. 2006. Global observed changes in daily climate extremes of temperature and precipitation. Journal of Geophysical Research 111: D05109, DOI: 10.1029/2005JD006290.

Alexandersson H. 1986. A homogeneity test applied to precipitation data. Journal of Climatology 6: 661-675.

Andreoli RV, Kayano M. 2005. ENSO-Related rainfall anomalies in South America and associated circulation features during warm and cold Pacific Decadal Oscillation regimes. International Journal of Climatology 25: 2017-2030, DOI: 10.1002/joc.1222.

Boulanger J-P, Leloup J, Penalba O, Rusticucci M, Lafon F, Vargas W. 2005. Observed precipitation in the Paranà-Plata hydrological basin: long-term trends, extreme conditions and ENSO teleconnections. Climate Dynamics 24: 393-413, DOI: 10.1007/s00382-0040514-x.

Buishand T. 1982. Some methods for testing the homogeneity of rainfall records. Journal of Hydrology 58: 11-27.

Frich P, Alexander LV, Della-Marta P, Gleason B, Haylock M, Klein Tank AMG, Peterson T. 2002. Observed coherent changes in climatic extremes during the second half of the twentieth century. Climate Research 19: 193-212.

Hawkins M. 1977. Testing a sequence of observations for a shift in location. Journal of the American Statistical Association 72: $180-186$.

Haylock MR, Peterson TC, Alves LM, Ambrizzi T, Anunciacao YMT, Baez J, Barros V, Berlato MA, Bidegain M, Coronel G, Corradi V, Garcia VJ, Grimm AM, Karoly D, Marengo JA, Marino MB, Moncunill DF, Nechet D, Quintana J, Rebello E, Rusticucci M, Santos JL, Trebejo I, Vincent LA. 2006. Trends in total extreme South American rainfall in 1960-2000 and links with sea surface temperature. Journal of Climate 19: 1490-1512.

Hoel P. 1971. Introduction to Mathematical Statistics. Wiley: New York, USA; 409.

Kayano MT, Andreoli R. 2007. Relations of South American summer rainfall interannual variations with the Pacific Decadal Oscillation. International Journal of Climatology 27: 531-540, DOI: $10.1002 /$ joc. 1417 .

Mantua NJ, Hare SR, Zhang Y, Wallace JM, Francis RC. 1997. A Pacific interdecadal climate oscillation with impacts on salmon production. Bulletin of the American Mateorological Society $\mathbf{7 8}$ : 1069-1079.

Percival DB, Walden AT. 1993. Spectral Analysis for Physical Applications. Cambridge University Press: Cambridge, UK; 580.

Peterson T, Easterling D, Karl T, Groisman P, Nicholls N, Plummer N, Torok S, Auer I, Boehm R, Gullett D, Vincent L, Heino R, Tuomenvirta H, Mestre O, Szentimrey T, Salinger J, Førland E, Hanssen-Bauer I, Alexandersson H, Jones P, Parker D. 1998. Homogeneity adjustments of In Situ atmospheric climate data: A review. International Journal of Climatology 18: 1493-1517.

Robertson AW, Mechoso CR. 1998. Interannual and decadal cycles in river flows of southeastern South America. Journal of Climate 11: 2570-2581.

Rusticucci M, Barrucand M. 2001. Climatología de Temperaturas Extremas en la Argentina, Consistencia de Datos. Relación entre la Temperatura Media Estacional y la Ocurrencia de Días Extremos. Meteorológica 26: 69-83. 
Rusticucci M, Vargas W. 2001. Interannual variability of temperature spells over Argentina. Atmósfera 14: 75-86.

Rusticucci M, Vargas W. 2002. Cold and warm events over Argentina and their relationship withy the ENSO phases: Risk evaluation analysis. International Journal of Climatology 22: 467-483.

Rusticucci M, Barrucand M. 2004. Observed trends and changes in temperature extremes over Argentina. Journal of Climate 17(20): 4099-4107.

Rusticucci M, Venegas S, Vargas W. 2003. Warm and cold event in Argentina and their relationship with South Atlantic and South Pacific sea surface temperatures. Journal of Geophysical Research 108: 3356, DOI: 10.1029/2003JC001793.

Sen PK. 1968. Estimates of the regression coefficient based on Kendall's Tau. Journal of the American Statistic Association 63: 1379-1389.

Smith TM, Reynolds RW. 2004. Improved extended reconstruction of SST (1854-1997). Journal of Climate 17: 2466-2477.

Trenberth KE. 1990. Recent observed interdecadal climate changes in the northern hemisphere. Bulletin of the American Meteorological Society 71: $988-993$.
Vera C, Silvestri G, Barros V, Carril A. 2004. Differences in El Niño response over the southern hemisphere. Journal of Climate 17: $1741-1753$.

Vincent LA. 1998. A technique for the identification of inhomogeneities in Canadian temperature series. Journal of Climate 11: 1094-1104.

Vincent LA, Zhang X, Bonsal BR, Hogg WD. 2002. Homogenization of daily temperature over Canada. Journal of Climate 15: $1322-1334$.

Vincent L, Peterson T, Barros V, Marino M, Rusticucci M, Carrasco G, Ramirez E, Alves L, Ambrizzi T, Berlato M, Grimm A, Marengo M, Molion L, Moncunill D, Rebello E, Anunciacao Y, Quintana J, Santos J, Baez J, Coronel G, Garcia J, Trbejo I, Bidegain M, Haylock M, Karoly D. 2005. Observed trends in indices of daily temperature extremes in South America 1960-2000. Journal of Climate 18: 5011-5023.

Wijngaard JB, Klein Tank AMG, Konnen GP. 2003. Homogeneity of 20th century European daily temperature and precipitation series. International Journal of Climatology 23: 679-692.

Zhang Y, Wallace M, Battisti D. 1997. ENSO-like Interdecadal Variability: 1900-93. Journal of Climate 10: 1004-1020. 